\title{
Lessons from Capital Market History
}

POPULAR BELIEFS AND STYLIZED FACTS

By Harry S. Marmer, CFA

A recent CFA Institute Magazine article asked the formidable question, "Should financial history matter to investors?" The author cited the results of a CFA Institute member survey, reporting that "when asked about the importance of economic and financial history to their success as investment professionals," an overwhelming majority (96\%) answered that it was either very or somewhat important. ${ }^{2}$

However, the same article noted that "some may not know how to use this knowledge to make better investment decisions (or, at the very least, avoid poor ones)." 3 The objective in this article is to illustrate how the study of capital market history can provide investors with "helpful guidance on how historical perspectives can be incorporated into investment decision-making processes." ${ }^{4}$ To demonstrate the point, I examine popular beliefs and their inconsistency with several stylized facts of long-term capital market data. ${ }^{5}$ Along the way, I provide specific and important suggestions for analyzing financial data and present selected lessons and facts investors can employ in their long-term decision-making process. Let's begin our journey through capital market history.

\section{BUSINESS AND STOCK MARKET CYCLES ARE PREDICTABLE}

The popular financial press often features investment professionals predicting the direction of the business cycle or the stock market. This behavior leads investors to believe that business and stock market cycles repeat in a predictable manner. Typical educational sources imply this predictability using a classical smooth-waved chart to illustrate the business cycle. Even employing the word cycle to describe longterm business and stock market movements reinforces the idea that these

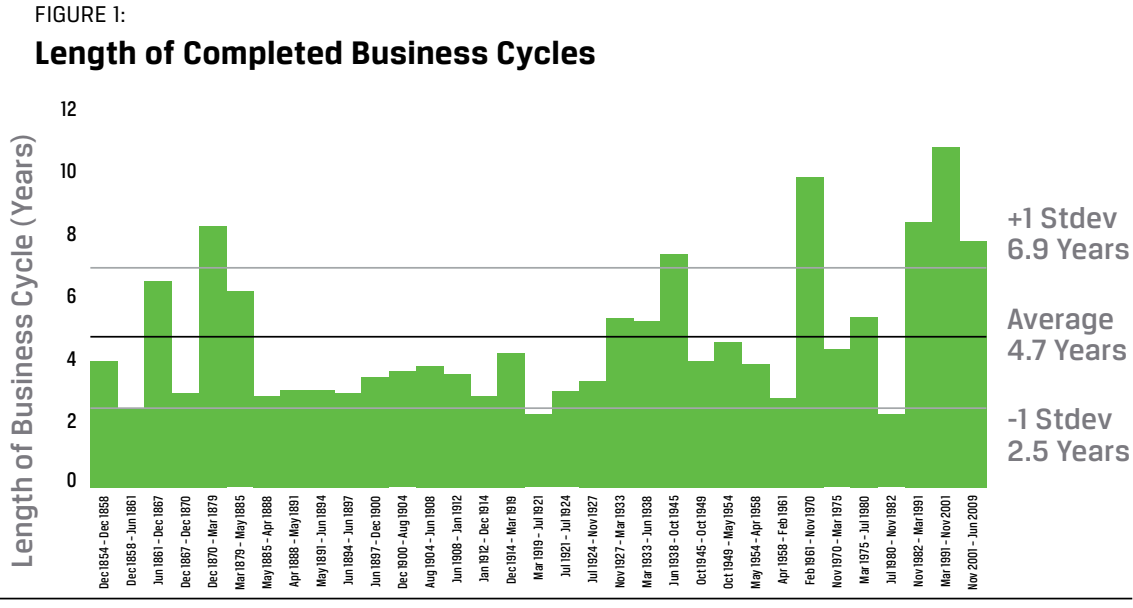

Sources: The National Bureau of Economic Research and Hillsdale Investment Management. Note: Business cycles above are based on trough-to-trough analysis.

"patterns" represent predictability and repeatability.

In examining long-term capital market data, it is often helpful to depict this quantitative information visually in order to better assess the evidence and determine if there are any particular patterns. ${ }^{6}$ In addition, visually inspecting the data is a good habit to develop in order to detect potential input errors.

Figure 1 shows 155 years of US business cycle history. Visually inspecting the long-term data gives one the impression that there is little predictability or cyclicality in the series. "This is perhaps an inevitable outcome given the changing nature of business cycles," wrote Serena Ng and Jonathan H. Wright in a 2013 article. "The fact that business cycles are not all alike naturally means that variables that predict activity have performance that is episodic."

Statistics for completed business cycles from 1854-2009 support this view. The "typical" US business cycle length over this time period averages 4.7 years (with a high degree of variability, as the standard deviation of the average cycle is 2.2 years). ${ }^{8}$ In other words, the underlying length of the business cycle has broadly ranged anywhere from 2.5 years to 6.9 years $68 \%$ of the time.

Stock market cycle statistics for the period between 1926 and 2016 support the fact that the length of a typical stock market is highly variable, averaging 7 years with a standard deviation of 3.1 years (i.e., $68 \%$ of the time a stock market can range from 3.9 years to 10.1 years).

Since the length of business and stock market cycles is highly variable and not predictable, investors should avoid investment and policy decisions predicated on attempting to predict the length or the turning point of either business or stock market cycles. ${ }^{9}$ The historical data also suggests that money managers should be assessed over longer periods than the standard three or four years, as the average stock market cycle is seven years.

Predicting the duration of the business cycle was aptly summarized by noted business-cycle analyst Victor Zarnowitz, who said, "Few business cycle peaks are successfully predicted; indeed, most are publicly recognized only with lengthy delays." 10 


\section{STOCK RETURN DISTRIBUTIONS ARE NON-NORMAL}

Investors employ market timing as a strategy if they believe they can "call the turns" in the market. ${ }^{11}$ Let us examine the challenges in implementing this strategy.

Figure 2 presents the distribution of monthly returns for the S\&P 500 Index over the past 89 years. This distribution appears non-normal, with long "fat" tails and a more peaked center in comparison to a normal return distribution. ${ }^{12}$

The abnormal shape of the distribution in Figure 2 represents, to some degree, the fact that stock returns are characterized by jumps. ${ }^{13}$ More specifically, financial prices tend to "jump, skip, and leap" up and down rather than change in a continuous fashion. ${ }^{14}$ As Svetlozar Rachev, Christian Menn, and Frank Fabozzi wrote in their book Fat-Tailed and Skewed Asset Return Distributions, "Heavy or fat tails can help explain larger price fluctuations for stocks over short time periods," resulting in a significant percentage of very good (and bad) returns occurring over a limited number of days. ${ }^{15}$

Why do markets behave in this fashion? Noted mathematician and scientist Benoit Mandelbrot proposes that one possible source for these empirical traits is the world outside the markets, or "exogenous effects."16 Continuing with this theme, respected quant Paul Kaplan suggests that financial crises and bank failures, which have

FIGURE 2:

\section{Distribution of Stock Market Returns}

S\&P 500 Monthly Return Relative Frequency, Jan. 1927-Mar. 2016

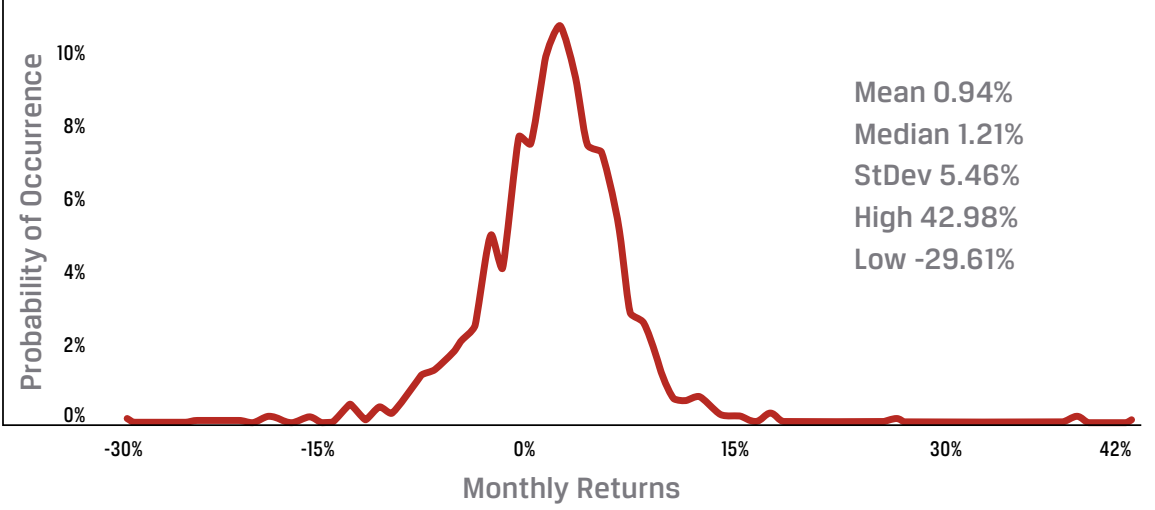

Source: Hillsdale Investment Management

occurred throughout history, are to blame for fat-tailed return distributions. ${ }^{17}$ Others point at investor behaviorial biases as a primary driver of the heavy or fat tails in asset-class return distributions. $^{18}$

The non-normal distribution of stock returns helps explain why market timing has often been described as a "mug's game," or a low-odds strategy, as illustrated in Figure 3. ${ }^{19}$

In this example, $\$ 1,000$ invested in the market more than doubled over 10 years, but missing just the 10 best days resulted in virtually no growth of capital. Of course, the flip side-missing the 10 worst days of market performance-presents the same challenge for investors. An intuitive rationale for the challenge in calling market turns is that the skill level required for market timing success is very high due

FIGURE 3:

Opportunity Costs of Missing Market Performance: \$1,000 Invested S\&P 500 Index, Daily, 10 Years Ending 30 June 2016

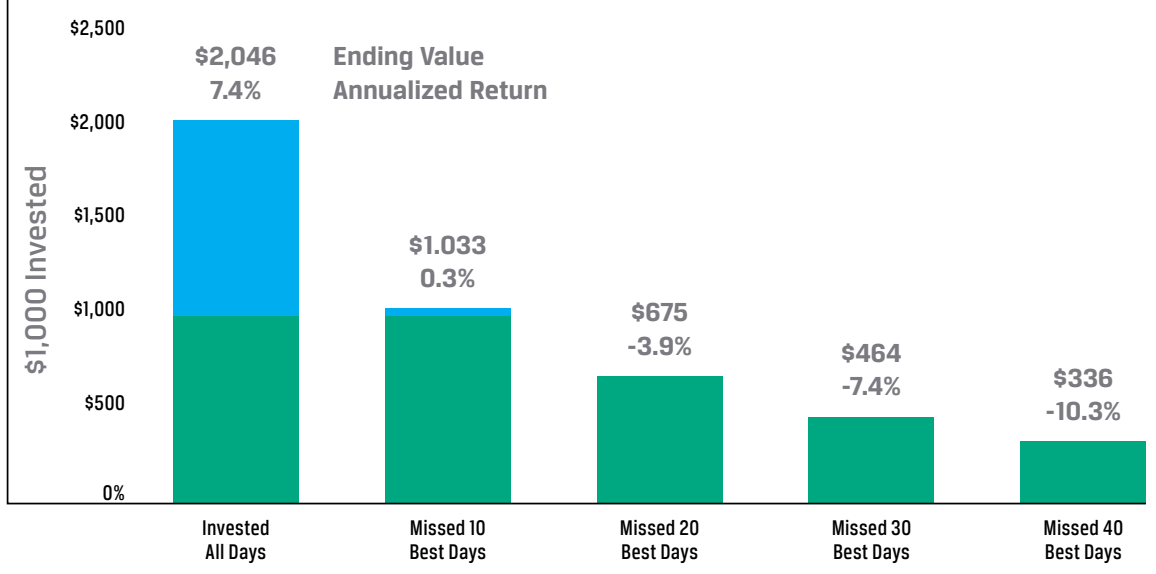

Source: Hillsdale Investment Management

EOUITY MARKETS ARE MORE VOLATILE

A popular current argument is that equity markets have become more volatile over time. This has been a prime motivation for institutional investors moving assets away from stocks into alternatives such as real estate, private equity, and infrastructure, which appear less volatile than stocks.

The empirical research presented in Figure 4 supports the following stylized facts concerning stock market return volatility: ${ }^{22}$

- Volatility is negatively correlated with returns (i.e., volatility rises during "bad" times like recessions or bear markets). 
FIGURE 4:

Equity Market Volatility Over Time: Monthly Rolling One-Year Data

S\&P 500 Index 1-Year Rolling Annualized Volatility, Monthly, Jan. 1926-Dec. 2015

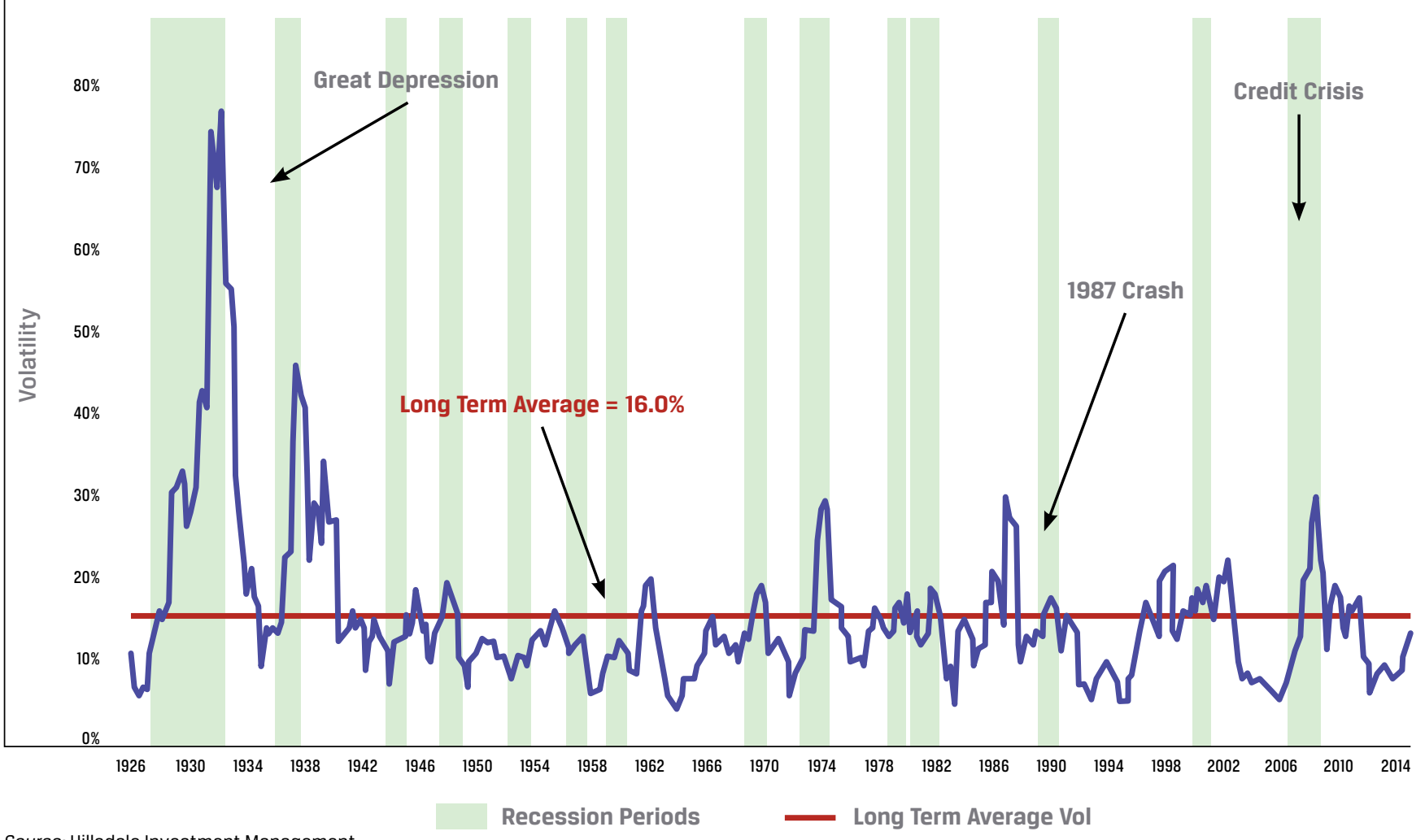

Source: Hillsdale Investment Management

FIGURE 5:

Equity Market Volatility Over Time: Monthly Rolling 10-Year Data

S\&P 500 Index 10-Year Rolling Annualized Volatility, Monthly, Jan. 1926-Dec. 2015

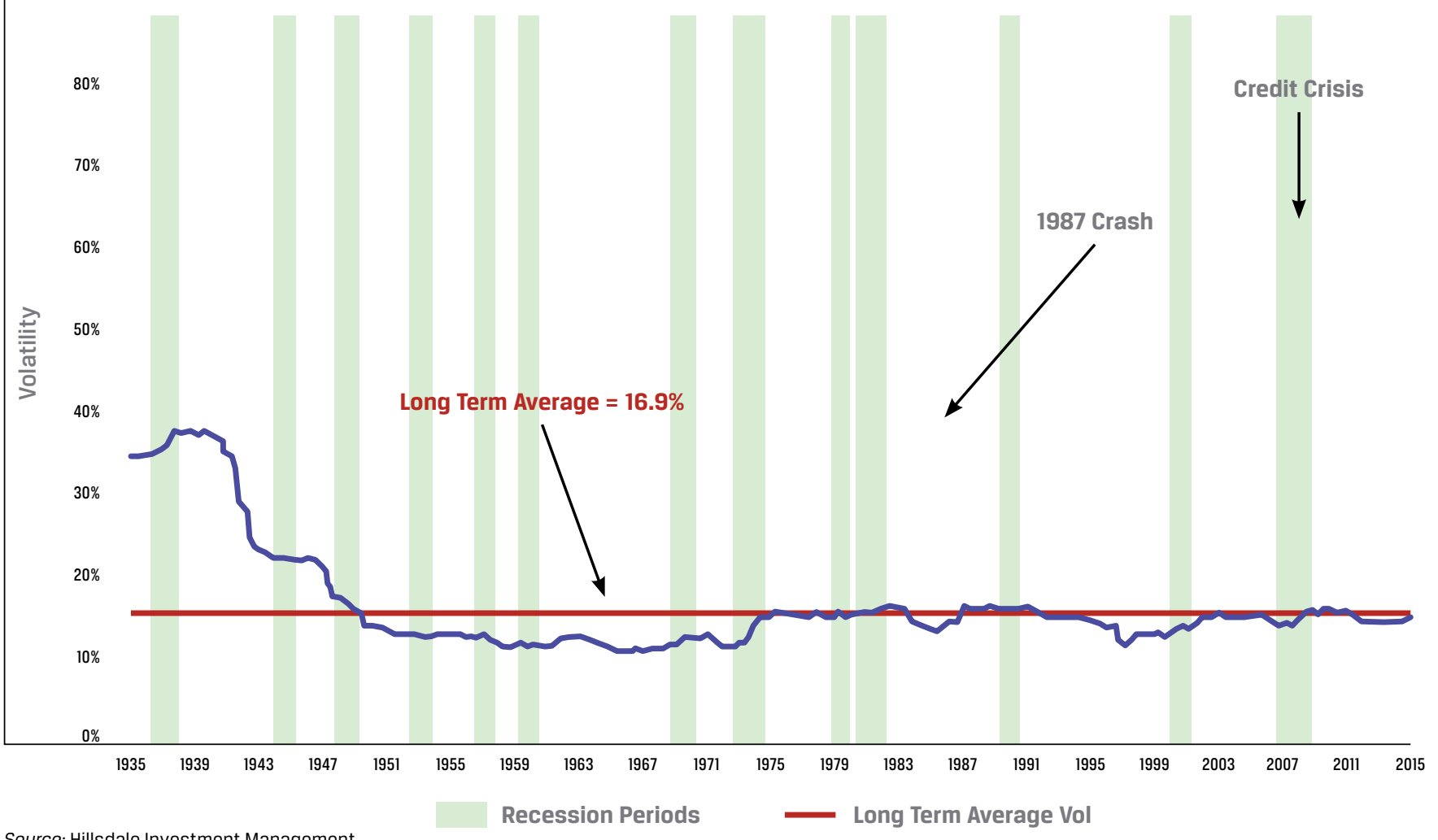

Source: Hillsdale Investment Management 
- Volatility persists or clusters; large changes follow large changes, in either direction, and small changes follow small changes.

- These observations lead to the conclusion that volatility reverts to the mean.

An important axiom we can derive from these stylized facts is that the frequency of calculating data matters, especially with respect to the interpretation of the data. ${ }^{23}$ More specifically, if investors use a long-term investment horizon (such as 10 years, which is similar in length to that used by private equity investors), public equity volatility will appear to be very stable (see Figure 5).

There is no doubt that investor views on volatility have been influenced by the increasing focus on short-term indicators, such as the Chicago Board Options Exchange Volatility Index (the VIX), which has become a popular indicator of market risk. ${ }^{24}$ In Figure 6, a visual examination of the history of rolling 30-day volatility (as a proxy for the VIX) illustrates that short-term volatility has spiked significantly more often, and with much higher spikes, than a longer-term measure of stock market volatility. This aspect is reflected in the statistically significant higher standard deviation of volatility for the 30-day volatility time series than the standard deviation for the monthly rolling 10 -year volatility (10.0\% for the VIX, versus 6.6\%).

\section{HISTORY REPEATS ITSELF}

Investors often study the past in the hope that history repeats itself. However, the ultimate lesson that one learns from studying capital market history is that "history never repeats itself exactly; at best it rhymes." This fact becomes very clear when history is used in an attempt to understand and evaluate the current interest rate environment. A review of interest rates in Figure 7 reveals that over the past 60-plus years, no historical environment is comparable to the current environment of low inflation and negative real yields. Dick Sylla, co-author of A History of Interest Rates, was quoted in the Wall Street Journal as stating that "There were no negative bond yields in 5,000 years of recorded history." ${ }^{25}$ This reflects the stylized fact that "the ex-post real interest rate is essentially random with means and variances that are different" over various periods and subject to jumps caused by structural events. ${ }^{26}$

Looking back in time does provide insight into the many long-term drivers of nominal and real interest rates. More specifically, a recent study of long-term interest rates by the Council of Economic Advisers concluded that these key drivers include "the rate of productivity growth, beliefs about future risks, consumer preferences, demographic shifts, and the stances of monetary and fiscal policy." ${ }^{27}$ Comprehending longterm drivers can help investors understand and recognize regime shifts and adjust their capital market assumptions with respect to determining policy asset mixes, thereby improving the decisionmaking process. ${ }^{28}$

\section{CONCLUSION}

The interpretation of historical data from which to test investment hypotheses is a key role for an analyst. For that purpose, some important, although basic, techniques can be recommended for analyzing and assessing capital market data: developing a hypothesis, visually inspecting the data, analyzing the entire return distribution, and recognizing that data frequency matters with respect to data interpretation and the investment decision-making process.

In summary, the following lessons can be employed by investors to help achieve their investment objectives and invest wisely for the long term: ${ }^{29}$

- Avoid investment and policy investment decisions that are dependent on predicting the length of or the turning points in the business or stock cycle.

- Properly assessing money managers requires a period longer than the typical three or four years.

- Market timing should be avoided because it is a low-odds strategy.

- Equity market volatility is time varying and has not significantly increased over time. Investor perceptions have been skewed by short-term metrics.

- Regime shifts create "new" investment environments that have an impact on capital market assumptions and on the investment decision-making process.

Indeed, investors can learn a great deal from the study of capital market history. Winston Churchill said it best: "Study history, study history. In history lies all the secrets of statecraft."

Harry S. Marmer, CFA, is a partner at Hillsdale Investment Management and a member of CFA Society Toronto.

The author would like to thank the following people for their helpful comments: Chris Guthrie, Kristin Spate, Michael Campbell, Paul Fahey, Peter Jarvis, Roger Clarke, Stephen Beinhacker, and Ari Veittiaho. All data presented are from Hillsdale's proprietary database unless indicated otherwise. 
FIGURE 6:

Equity Market Volatility Over Time: 30-Day Volatility Annualized

S\&P 500 Index 30-Day Rolling Annualized Volatility, Jan. 1928-Dec. 2015

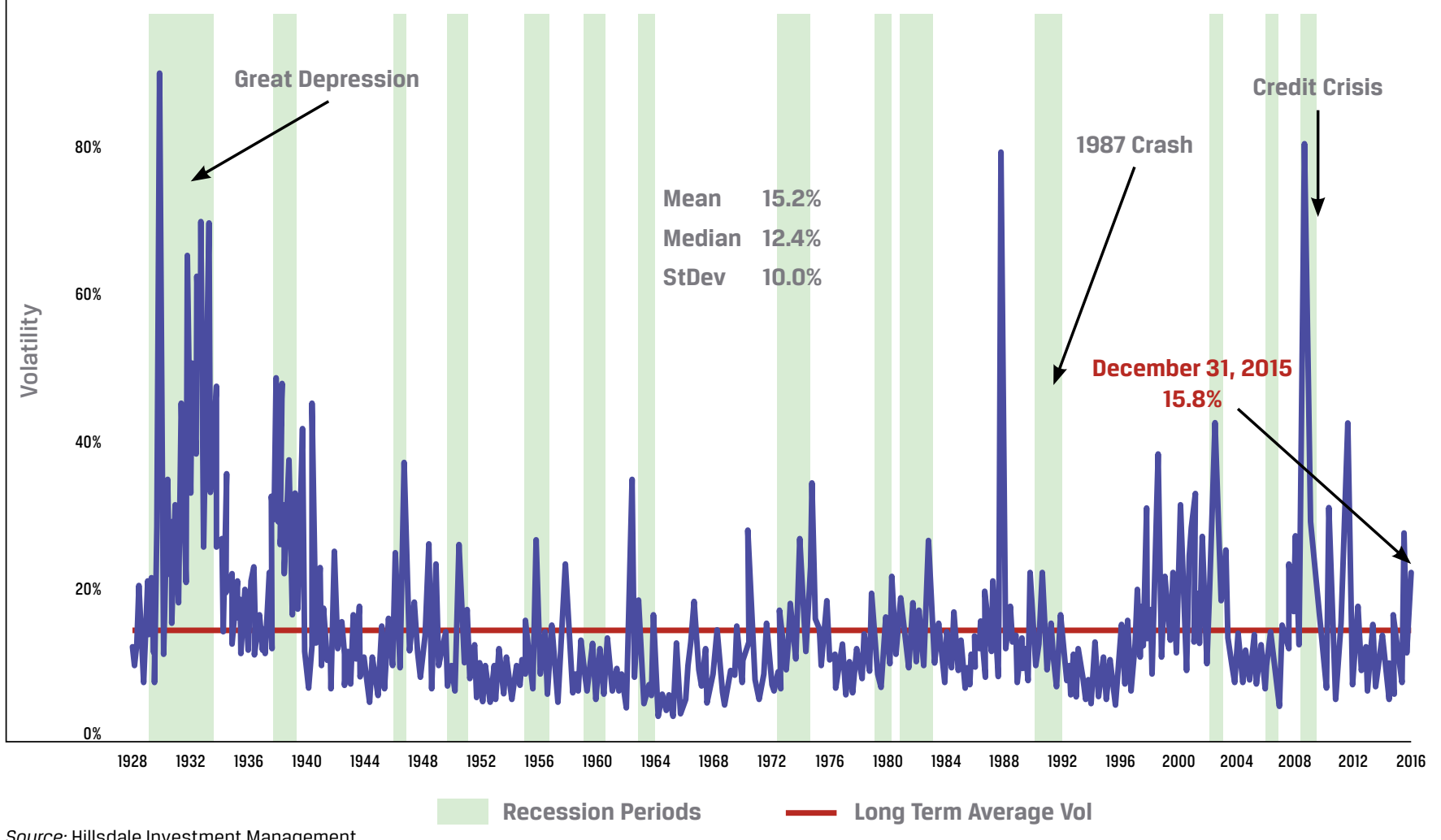

Source: Hillsdale Investment Management

FIGURE 7:

Interest Rate Regimes

Interest Rate Regimes Classified By Inflation Environment*, Monthly, Jan. 1951-Dec. 2015
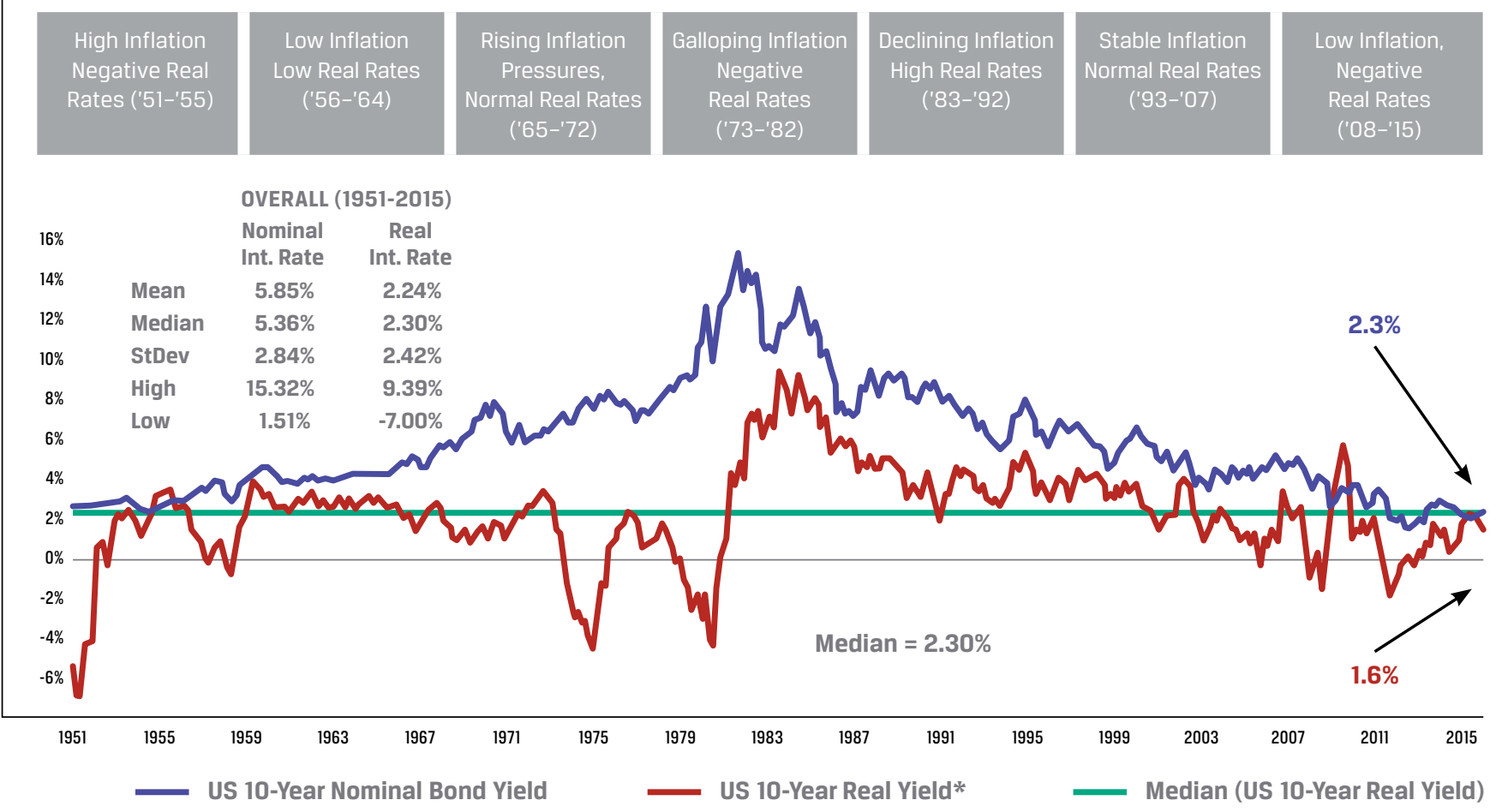

* The Real 10-Year US Treasury Yield is based on 10-Year US Treasury Inflation-Indexed Yield, Constant Maturity from January 2003 to June 2013.

Data prior to January 2003 are based on 10-Year US Treasury Bond Yield vs. 12-Month Change in US CPI. Data as of 31 December 2015.

Source: Hillsdale Investment Management. 
1 See Allevato (2015).

2 Ibid.

3 Ibid.

4 Ibid.

5 A "stylized" fact refers to "empirical findings that are so consistent across markets that they are accepted as truths." See Sewell (2011).

6 For a further discussion of the benefits of depicting quantitative data, see Tufte (1997 and 2001).

7 See $\mathrm{Ng}$ and Wright (2013, p. 1149).

8 The high degree of variability in the length of the stock market cycle supports the famous quotation by Nobel Prize-winning economist Paul Samuelson: "The stock market has forecast nine of the last five recessions." Quoted in Bluedorn, Decressin, and Terrones (2013, p. 4).

9 The failure of experts in predicting the length of either the business cycle or the stock market cycle is discussed in more detail in Siegel (2013, ch. 15).

10 See Zarnowitz (1998).

11 For a further discussion of the challenges in market timing, see Lawton (2015).

12 In Figure 2, the kurtosis for this distribution is 9.7; a normal distribution is 3 . Dealing with non-normal return distributions is discussed in more detail in Rachev, Menn, and Fabozzi (2005). The pioneering work on non-normal stock return distributions was led by Benoit Mandlebrot, who illustrated that "the tails of the distributions of price changes are in fact extraordinarily long, that the sample second moments typically vary in an erratic fashion." See Mandelbrot (1963, p. 394-419). Today, it is an accepted principle that "asset class return distributions are not normally distributed" and returns are better described by nonnormal return distributions with skewed and fat-tailed distributions. See Xiong and Idzorek (2011, p. 23). For an excellent review of the properties of asset returns, see Cont (2001, p. 223-36).

13 Evidence on jumps in stock returns is discussed in more detail in Das and Uppal (2004).
14 See Hudson and Mandelbrot (2004, p. 237). Mandelbrot is a pioneer in applying fractal geometry to markets. This book is a must-read for all capital market students.

15 Rachev, Menn, and Fabozzi (2005, p. 1).

16 Hudson and Mandelbrot (2004, p. 228).

17 Kaplan (2012, ch. 17-20 and 26). The excellent Frontiers of Modern Asset Allocation collects Paul Kaplan works discussing the underlying economic thought surrounding, and possible explanations for, financial crises, return distributions, and fat tails, among other topics.

18 Rachev, Menn, and Fabozzi (2005), for example.

19 Theoretical studies support this hypothesis, finding that a sizable success ratio of anywhere from $60 \%$ to $70 \%$ is required to beat a buy-and-hold strategy. The experiences of professional forecasters and most empirical studies of active timers support this viewpoint. Clifford Asness, from another perspective, argues, "Factor timing is highly analogous to timing the stock market. Stock market timing is difficult and should be done in very small doses, if at all.” See Asness (2016).

20 Samuelson (2008, p. 6).

21 Much has been written about rebalancing policies and asset mix policies. The classic "Dynamic Strategies for Asset Allocation" (see Perold and Sharpe 1988) discusses four kinds of asset mix policies. A thorough review of rebalancing can be found in Maginn, Tuttle, Pinto, and McLeavey (2007), specifically in the chapters "Monitoring and Rebalancing" and "Capital Market Expectations." More recently, Campbell Harvey and others (see Granger, Harvey, Rattray, and Zou 2014) suggest that adding a momentum overlay would enhance the return-to-risk ratio of a constant-mix strategy.

22 Volatility negatively correlated with returns is known as the leverage effect, a.k.a. the asymmetric volatility phenomenon. These stylized facts on stock market return volatility are discussed in more detail in the following studies: Schwert (1989); Masset (2011); Osambela (2008); Poon and Granger (2003); Andersen, Bollerslev, Diebold, and Ebens (2001); and Marmer (2002).
23 Frequency refers to the periodicity (e.g., intra-day, daily, weekly, etc.) of the data and how it is used in the calculation. For example, the risk of an asset class, typically described as the standard deviation of returns for the asset class, could be calculated using daily, monthly, quarterly, or yearly return data measurement. As discussed later in this article, different frequencies can lead to significantly diverse results. This idea is discussed in more detail in Goetzmann and Edwards (1994) and more recently in Boguth, Carlson, Fisher, and Simutin (2016). Though it is beyond the scope of this paper to discuss the inputs for portfolio optimization, solutions for handling portfolio optimization are discussed in Michaud and Michaud (2008).

24 Sicherman, Loewenstein, Seppi, and Utkus (2016) discuss this topic in more detail.

25 See Freeman (2016).

26 See Garcia and Perron (1996).

27 See Executive Office of the President of the United States (2015, p. 40).

28 For an excellent review of how to set capital market assumptions, see "Capital Market Expectations" in Maginn, Tuttle, Pinto, and McLeavey (2007). The concept of regime shifts and model selection is discussed in more detail in Fabozzi, Focardi, and Kolm (2006, ch. 5 and 7). The effect of differing economic scenarios on investment decision making is discussed in Marmer, Heyer, and McInerney (1997). Regime shifts and asset allocation are discussed in Marmer (1991).

29 The concept of "avoiding mistakes and investing wisely" can be traced back to Psalms 34:14, where we find the Psalmist suggesting that "one should leave evil and do good." Goyal, Ilmanen, and Kabiller (2015) take a similar approach in "Bad Habits and Good Practices." 
Allevato, Desi. 2015. "Should Financial History Matter to Investors?" CFA Institute Magazine, vol. 26, no. 5 (September/ October): 26-30.

Andersen, Torben G., Tim Bollerslev, Francis X. Diebold, and Heiko Ebens. 2001. "The Distribution of Realized Stock Return Volatility." Journal of Financial Economics, vol. 61, no. 1 (July): 43-76.

Asness, Clifford S. 2016. "The Siren Song of Factor Timing." Journal of Portfolio Management, Special Issue, no. 1: 1-6. Bluedorn, John C., Jörg Decressin, and Marco E. Terrones. 2013. "Do Asset Price Drops Foreshadow Recessions?" IMF Working Paper WP/13/203: 1-34.

Boguth, Oliver, Murray Carlson, Adlai Fisher, and Mikhail Simutin. 2016. "Horizon Effects in Average Returns: The Role of Slow Information Diffusion." Review of Financial Studies, vol. 29, no. 8 (August): 2241-81.

Cont, Rama. 2001. "Empirical Properties of Asset Returns: Stylized Facts and Statistical Issues." Quantitative Finance, vol. 1: 223-36.

Das, Sanjiv Ranjan, and Raman Uppal. 2004. "Systemic Risk and International Portfolio Choice." Journal of Finance, vol. 59, no. 6 (December): 2809-34.

Executive Office of the President of the United States. 2015. "Long-Term Interest Rates: A Survey.” July.

Fabozzi, Frank J., Sergio M. Focardi, and Petter N. Kolm. 2006. Trends in Quantitative Finance. Charlottesville, VA: The Research Foundation of CFA Institute.

Freeman, James. 2016. "The 5,000-Year Government Debt Bubble." Wall Street Journal, 31 August.

Garcia, René, and Pierre Perron. 1996. "An Analysis of the Real Interest Rate under Regime Shifts." Review of Economics and Statistics, vol. 78, no. 1 (February): 111-25. Goetzmann, William N., and Franklin R. Edwards. 1994. "Short-Horizon Inputs and Long-Horizon Portfolio Choice." Journal of Portfolio Management, vol. 20, no. 4 (June): 76-81.

Goyal, Amit, Antti Ilmanen, and David Kabiller. 2015. "Bad Habits and Good Practices." Journal of Portfolio Management, vol. 41, no. 4 (Summer): 97-107.
Granger, Nick, Campbell Harvey, Sandy Rattray, and David Zou. 2014. "The Unexpected Costs of Rebalancing and How to Address Them." AHL Partners (June): 1-14.

Hudson, Richard L., and Benoit Mandelbrot. 2004. The (Mis)Behavior of Markets: $A$ Fractal View of Risk, Ruin, and Reward. New York: Basic Books.

Kaplan, Paul D., ed. 2012. Frontiers of Modern Asset Allocation. Hoboken, NJ: John Wiley \& Sons.

Lawton, Phillip. 2015. "Calling the Turns: Why Market Timing Is So Hard." Research Affiliates (April), www.researchaffiliates. com/en_us/publications/articles/429 calling_the_turns_why_market_timing_is_ so hard.html

Maginn, John L., Donald L. Tuttle, Jerald E. Pinto, and Dennis W. McLeavey, eds. 2007. Managing Investment Portfolios: A Dynamic Process, 3rd ed. Hoboken, NJ: John Wiley \& Sons.

Marmer, Harry S. 1991. "Optimal International Asset Allocations under Different Economic Environments: A Canadian Perspective." Financial Analysts Journal, vol. 47, no. 6 (November/ December): 85-92. 2002. Perspectives on Institutional Investment Management. Toronto: Rogers Publishing.

Marmer, Harry S., Martin Den Heyer, and Barry McInerney. 1997. "An Introduction to Real Return Bonds for the Institutional Investor." William M. Mercer (March): 1-24.

Masset, Philippe. 2011. "Volatility Stylized Facts." University of Fribourg, September.

Michaud, Richard O., and Robert O. Michaud. 2008. Efficient Asset Management: A Practical Guide to Stock Portfolio Optimization and Asset Allocation, 2nd ed. New York: Oxford University Press.

Ng, Serena, and Jonathan H. Wright. 2013. "Facts and Challenges from the Great Recession for Forecasting and Macroeconomic Modeling." Journal of Economic Literature, vol. 51, no. 4: 1120-54. Osambela, Emilio. 2008. "Understanding Stock Return Volatility." Swiss National Centre of Competence in Research
(FINRISK), 10 November.

Perold, André F., and William F. Sharpe. 1988. "Dynamic Strategies for Asset Allocation." Financial Analysts Journal, vol. 44, no. 1 (January/February): 16-27.

Poon, Ser-Huang, and Clive W.J. Granger. 2003. "Forecasting Volatility in Financial Markets: A Review." Journal of Economic Literature, vol. 41, no. 2 (June): 478-539.

Rachev, Svetlozar T., Christian Menn, and Frank J. Fabozzi. 2005. Fat-Tailed and Skewed Asset Return Distributions: Implications for Risk Management, Portfolio Selection, and Option Pricing. Hoboken, NJ: John Wiley \& Sons.

Samuelson, Paul. 2008. "Canny Portfolios." CFA Institute Magazine, vol. 19, no. 1 (January/February): 6.

Schwert, G. William. 1989. "Why Does Stock Market Volatility Change over Time?" Journal of Finance, vol. 44, no. 5 (December): 1115-53.

Sewell, Martin. 2011. "Characterization of Financial Time Series." UCL, Department of Computer Science, 20 January.

Sicherman, Nachum, George Lowenstein, Duanne Seppi, and Stephen Utkus. 2016. "Financial Attention." Review of Financial Studies, vol. 29, no. 4 (April): 863-97.

Siegel, Jeremy J. 2013. Stocks for the Long Run, 5th ed. New York: McGraw-Hill Education.

Tufte, Edward R. 1997. Visual Explanations: Images and Quantities, Evidence and Narrative. Cheshire, CT: Graphics Press. 2001. The Visual Display of Quantitative Information, 2nd ed. Cheshire, CT: Graphics Press.

Xiong, James X., and Thomas M. Idzorek. 2011. "The Impact of Skewness and Fat Tails on the Asset Allocation Decision." Financial Analysts Journal, vol. 67, no. 2 (March/ April): 23-35.

Zarnowitz, Victor. 1998. "Has the Business Cycle Been Abolished?" Business Economics, vol. 33, no. 4 (October): 39-45. 